\title{
A Critical Genre Analysis of Negative Parts in CSR Reports
}

\author{
Shuai Liu ${ }^{1 *}$ \\ ${ }^{1}$ School of Foreign Studies, University of Science and Technology Beijing, Beijing, 100083, China \\ *Corresponding author. Email: b20180433@xs.ustb.edu.cn
}

\begin{abstract}
This study analyses the representations of negative part especially the safety performance in CSR report. Drawing on critical genre theory, we examined 20 safety parts from 20 American company, and has found that 3 major moves and 11 steps were presented. The study illustrates how diverse types of discourse on the same genre could facilitate the realization of professional culture and enhance the understanding of the professional nature of negative part of in the CSR report of corporate communication. It calls for greater focus on the internal and external analysis of the negative aspect of aspects of companies' self-disclosure.
\end{abstract}

Keywords: CSR reports, negative parts, critical genre analysis, rhetorical move

\section{INTRODUCTION}

CSR reports refer to the corporate undertaking in response to environmental damages, employment discrimination, and unethical practices [9]. CSR reports provides value-relevant information to investors [6],[13]; in this sense, negative information in the CSR reports can thus cause unsatisfied financial performance and corporate profit [1]. Thus, it poses a challenge for the companies to deal with the negative parts of their CSR performance. Therefore, it is an urgent task to confront such a challenge. Under such practical pressure, vast studies have investigated the negative parts in CSR reports (e.g. [18],[19],[22]). However, most of these studies only touch the internal or only the lexical-grammar part of this genre, but few studies explored the external factors that determine the communicative purpose of this genre, in order to fill this gap, we aim to analyze the rhetorical structure of negative parts of in CSR report and the external context of it in major companies that listed in the fortune 500. The remainder of the paper is organized as follows. Section 2 offers a literature review of CSR. In order to fill this gap, we aim to analyze the rhetoric reports and negative disclosure in CSR reports. Section3 discusses the corpora and the theoretical foundation of this study. Section 4 reports the major findings and discussion. In the final section, we conclude our study's limitation and future direction. This study is guided by the following two research questions:

Research question1: what are the rhetorical move and its linguistic resources in the negative parts of CSR reports? Research question2: what kinds of rhetorical moves are used in negative parts in CSR reports?

\section{LITERATURE REVIEWS}

Previous studies on the linguistic aspect of negative parts of CSR reports can be divided into two strands. The first is mainly from the "form" of the language [21].

The first is mainly from the "content" of the language, reference [11] examined the negative disclosure released by197 Australian companies from 1980 to 1991 and reveals that not all companies provided the provision of six types of 'negative environmental disclosures [11] Recently, the study by [15] closely analysed the sustainability performances, and their results suggest that the company that has a weak financial performance is likely to a high percentage of negative disclosure. In addition, their thematic content analysis research showed that the negative disclosure is often long and hard to read. However, as stated by Uribe and Gunter, the analysis of content's themes alone does not account for all potential linguistic characteristics in the reports [22 p 210].

In order to give a response to /echo the above-mentioned methodological challenges, some scholars adopt a discourse analysis method, of which the concept of discourse is regarded as a social practice [17]. With the aid of discourse analysis, it will drill and analyze underpinning discursive and textual choices that have been deployed to achieve certain communication purpose. Moreover, within the method of discourse analysis, the genre analysis [2] stands as an important analytical method. As the tenet of genre analysis goes like this 'as the communicative purpose is regarded as an important indicator in determining how to use the language in achieving certain goals in a specific social context. Although much small in scope, there exists some studies on CSR disclosure [12],[10]. Reference[12] analyzed the two subgenres of corporate environmental reports and illustrated the major moves in such genre (announcing the company's environmental policy and objectives, its environmental 
performance and Etc.). Following the line of [12], reference [10] further identified four macro moves and eight component sub-moves of the CSR reports that some large Western companies in released in 2000 and 2007. Despite the dominant emphasis is placed on the macro genre of CSR reports. A few studies that focus on the negative disclosure of CSR reports. For example, Reference [22] investigated the occupational incidents in 92 CSR reports released by 37 Chinese companies listed in Fortune 500 List. This study, besides, provided practical information for professional communicators. Unfortunately, the study only analysed the lexical -grammar features of such genre, the features that are beyond the discourse level are hard to find. This study aims to fill the gap by adopting the CGA (critical genre theory), a theoretical model that attempts to exploit the way that professional discourse is not only attained through the textual but also from external factors [4],[5],[7].

However, the scope of research is rather limited because this study is only concerned with the CSR reports. In this paper, we attempt to analyze the negative part discourse from the perspective of CGA theory and hope to contribute a better understanding of such distinct types of business communication.

\section{CORPUS AND THEORETICAL BACKGROUND}

Traditionally, genre analysis has only focused on the text-internal factors (e.g., the generic constructs). and little attention has been paid to the text-external factors (e.g., the context) [4]. However, the role of context is important for achieving certain professional actions. In order to tackle such theoretical limitation, Bhatia proposed the CGA theory, which focuses on the demystification of professional practice through the medium of genres and aims to provide and reinforce our understanding of and inclination for the organization of professional genres and actions [4], it states that professional practice, interdiscursivity and multi-perspectives are the essence of CGA. with the popularity of CGA, it has been applied into the analysis of the business discourse the MD\&A discourse in the annual report [21]. This study aims to expand the application of CGA research by analysing the interdiscursivity, the professional culture in business communication.

The corpus of our study is compromised with 20 safety parts from 20 American companies, the size of our corpus is consistent with other studies that adopt rhetorical moves analysis in the ESP perspective [16], we chose these reports for our study for several reasons; First, the negative disclosure was chosen from those companies that is known to have major occupational incidents in their reports. In order to ensure the reliability of the coding, we follow the guideline for content analysis [8],[14], [20].

\section{FINDINGS AND DISCUSSION}

As we have already stated, the purpose of this part is to present a trustworthy company and also give narration of true safety performance of the company. Thus, the main issue of this parts is to convey the safety performance, the safety incidents and the safety endeavors. under such assumption, we find three major moves and 10 constituent steps in our corpus. As indicated in table 2, the three moves in negative parts of CSR reports are 'presenting the safety scene', followed by 'reporting safety disclosure' and 'prompting action'. In order to better understand the topic and purpose of each step, we will present each step with specific example for detailed analysis.

Table 1. Results of the rhetorical move of 20 negative parts in the sample reports

\begin{tabular}{|c|c|c|c|c|}
\hline Move & Step & $\begin{array}{l}\text { No sample reports } \\
\text { that containing step }\end{array}$ & Percentage & $\begin{array}{l}\text { No of sample reports that } \\
\text { containing step move }\end{array}$ \\
\hline \multirow{4}{*}{$\begin{array}{l}1 \text { Presenting the } \\
\text { safety scene }\end{array}$} & $\begin{array}{l}\text { 1a Presenting the importance of } \\
\text { safety }\end{array}$ & 16 & $80 \%$ & \multirow{4}{*}{20} \\
\hline & $\begin{array}{l}\text { 1b Showing safety } \\
\text { commitment/strategies }\end{array}$ & 20 & $100 \%$ & \\
\hline & 1c Showing safety value & 10 & $50 \%$ & \\
\hline & 1d Stating safety practice & 20 & $100 \%$ & \\
\hline \multirow{3}{*}{$\begin{array}{l}2 \text { Reporting safety } \\
\text { disclosure }\end{array}$} & $\begin{array}{l}\text { 2a Describing the overall safety } \\
\text { performance }\end{array}$ & 16 & $80 \%$ & \multirow{3}{*}{19} \\
\hline & $\begin{array}{l}\text { 2b Giving detailed safety } \\
\text { incidents }\end{array}$ & 3 & $15 \%$ & \\
\hline & $\begin{array}{l}\text { 2c Judging the safety } \\
\text { prevention measure }\end{array}$ & 15 & $75 \%$ & \\
\hline
\end{tabular}




\begin{tabular}{|c|c|c|c|c|}
\hline \multirow{3}{*}{$\begin{array}{l}3 \text { Prompting } \\
\text { action }\end{array}$} & $\begin{array}{l}\text { 3a Timely reaction towards } \\
\text { specific safety accidents }\end{array}$ & 12 & $60 \%$ & \multirow{3}{*}{19} \\
\hline & 3b Expressing pity & 4 & $20 \%$ & \\
\hline & $\begin{array}{l}\text { 3c Promising better future } \\
\text { safety endeavor }\end{array}$ & 18 & $90 \%$ & \\
\hline
\end{tabular}

\subsection{Presenting the Safety Scene(move1)}

We find that the first move "presenting the safety scene" is included in all 20 reports in our corpus. As the title suggests, this moves provides the background information of the company's safety issues before delivering the safety incidents. As showed in table 2, this move contains three major steps:

1a presenting the importance of the safety

$1 \mathrm{~b}$ showing safety commitments

$1 \mathrm{c}$ showing safety values

$1 d$ stating safety practice

The first step "presenting the importance of the safety" is where the company stress that safety is highly valued in their management and business. As in the following examples:

Extract1: Exelon's talented, committed, and diverse workforce is critical to our company's future success. Workforce safety and health is our highest priority and we implement policies and programs that maintain a strong safety culture (america exelon 2018)

Extract2: Protecting the safety and health of our workforce is fundamental to our business. We are relentless in our pursuit of safety so every employee and contractor comes home from work each day safe and healthy. (America exxonmobil 2014)

In these two examples, the company used the expressions "our highest priority" and "is fundamental to" to emphasize that safety is of great importance to their business' operation

In addition to presenting the presenting the importance of the safety, in the next step of this move, most companies choose to show "safety commitment/strategies" (step 2), and this step was mentioned in all the 20 reports in our corpus. In this step, companies will elaborate the concrete plan that has been adopted in order to ensure their safety agenda. As can be seen in extract 3 and extract4:

Extract3: Our Contractor Health, Safety and Environment (HSE) Standard provides corporate HSE requirements for the company's contracting process. This process allows HSE risks to be identified and quantified using the ConocoPhillips Risk Matrix, ..."high and significant risks" require full implementation of the Contractor HSE Standard.

Extract4: A Pre-Qualification Assessment is conducted to prescreen potential contractors, which includes a review of contractor-supplied information. .... The HSE portion of the overall contractor evaluation process is based on a combination of trailing indicators such as injury rates and the completeness and functionality of the contractor's HSE management system.( america conocophlip 2014)

In extract 3 and 4 , safety strategies were performed by non-human actors ("Contractor Health, Safety and Environment (HSE) Standard", "A Pre-Qualification Assessment") it did not mention the specific department or person that take these safety strategies, thus it will reduce the chance of takin direct responsibility if some safety incidents were happened.

Some reports did not include the step "the important of safety", it often choose to give such information by discussing the "showing safety value" (move3), as can be seen from extract 5:

Extract 5: Safety is more than just a priority at ExxonMobil it is a core value. A commitment to safety is a value that shapes all decision-making at every level. (america exxomobil 2013)

In this extract, the company state that safety is one of the most cherished belief that treasured by the company, and the status is more than any other guidance, as can be seem from the expression 'shape all decision making'.

When it refers to the move 4 "stating safety practice", it also appeared in all the 20 reports. This step is about the specific measure that have been taken by the company. As can be seen from the extract 6 :

Extract 6: To reinforce DuPont Core Values, mandatory safety meetings are held each month. These meetings provide in-person training and updates on safety topics both inside and outside the workplace. Employees who are unable to attend these meetings must complete supplemental training offline. (america dupont 2018)

Extract 7:Valero has implemented an emergency preparedness program to ensure its response readiness. We train and prepare to make sure that in the event of an emergency, we do the best job possible to protect personnel, the community and our environment. ( Valero 2017)

In extract 6 and 7, a chain of concrete action verbs ,such as("held", "implemented", "train", "prepare") were deployed, thus highlighting the safety practice that the company had been put into operation.

\subsection{Reporting safety disclosure (move 2)}

The subsequent move, "reporting safety disclosure" is where the message that indicate about workplace fatalities and injuries. It comprises the following steps:

2 a describing the overall safety performance

$2 \mathrm{~b}$ giving the detailed safety incidents

$2 \mathrm{c}$ judging the safety prevention measure

$2 \mathrm{~d}$ explanation steps

Extract 8: In 2013, we progressed toward our goal of Nobody Gets Hurt. When compared with 2012, our workforce lost-time incident rate decreased by nearly 9 percent. Since the inclusion of XTO Energy in 2011, we have reduced our workforce lost-time incident rate by 45 percent. However, we are still not where we want to be. We deeply regret that six workers were fatally injured in five incidents related to ExxonMobil operations in 2013(america exxomibil 2013) Extract 9: In 2017, Valero recorded its lowest-ever refinery employee TRIR of 0.28 , well below the industry average for refinery employees of about 0.6 , and a 20 percent drop from the previous year. Our combined refinery employee and contractor rate stood at 0.32 (america valero 2017) 
Extract 10: in 2010, up to 80 percent of safety incidents occurred near the end of a project. In 2013, we reduced this number to approximately 10 percent and achieved zero in 2014 (america exxomobil2014)

As to the step 1 in move 2, it mainly gives the general safety information of the company in the past year, and more often, it uses some vague expression, such as "a 20 percent drop", decreased by nearly 9 percent), however, the figure is not concrete, the exact number of the fatalities or injures numbers is not provided.

When it refers to the second step in this move, the "Presenting the specific detail of certain workplace incident", it only appears in 3 of or corpus. Here is one example.

Extract 11: We deeply regret the fatal accidents that claimed the lives of five UPS employees in 2014, all of whom were men. Three of the fatalities involved auto accidents, while two involved a tragic workplace shooting. (UPS 2014).

As we can found from the above table, only a very few companies are willing to provide the detail of incident, such as the gender of the fatality, the cause of the incident. The possible reason for thar narration may be attributed to the fact that it is not a compulsory requirement by the guidance of CSR regulation.

In step 3 of move2, "judging the safety prevention measure" (2c), companies indicated that the rules or instruction is relevant to their positive safety performance.

Extract 12: An increased focus on verification of the Life Saving Rules in 2015 is believed to have contributed to the improvement in our serious incident rate. Business units are accountable for developing and implementing a field verification program that best suits the needs of the business. (america conocophilp 2015)

In most cases, this step is just followed the presentation of the overall performance of the company's safety performance, and this step is used to explain the good safety performance, as in this extract, we can find the words ("contribute", "are accountable for") that were used to indicate the causes.

\subsection{Prompting Action(move 3)}

Towards the last move 3, prompting action is used to give the information about the timely action and future after the certain incidents happened. This move contains three major steps:

3a timely reaction towards specific safety accidents

$3 \mathrm{~b}$ expressing pity

$3 \mathrm{c}$ promising better future safety endeavor

Step1 "timely reaction towards specific safety accidents" was only found in 12 in the reports in our corpus, in this move, company are often state that they respond to the incident with correct procedure, such as "providing rescue, carrying out thorough investigation".

Extract 13: Whenever an accident occurs on the job at UPS, our management invests a significant amount of attention investigating the contributing causes and improving procedures and safety training where necessary. (Ups 2014)
In this example, the company indicate their timely and appropriate responsible action after the occurrence of incidents, such as ("investigating the cause improving procedures").

expressing pity (3b) is about the attitude of the company towards the incident. An example is presented below:

Extract14: We at Exelon are deeply saddened by this loss of life. (America exelon 2018)

The company express a strong sympathy and sorrow ("deeply saddened"). In our corpus, only very few companies explicitly stated this step, and this is often used with the description of very serious incidents. And such phenomenon could be attributed to the rapport management reason.

promising better future safety endeavour (3c)

the last step of move 3 is about the future safety arrangement and effort that may ensure better future safety performance.

Extract 15: In 2019, we will continue to improve our programs and focus on serious injury and fatality prevention. (Exelon, 2018)

As indicated in extract, the company pledge to enhance their future safety plan ("will continue to improve").

\section{CONCLUSION}

By adopting the theory of critical genre analysis, this research has analyzed the bad information in the CSR report, it mainly elaborates the discussion of such discourse from the perspective of genre, professional practice.

In terms of the genre level, it had found 3 major moves and 11 steps, among these 11 steps, "presenting the importance of safety", "showing safety commitment/strategies", "describing the overall safety performance", "promising better future safety endeavour" similar to the finding of [21] negative part discourse also achieves the same goal of promoting a trust-worthy image by adopting these core steps.

The major contribution of the current study is that it enhances the understanding of the professional nature of negative part of in the CSR report of corporate communication, the study illustrates how diverse types of discourse on the same genre could facilitate the realization of professional culture. Despite the above-mentioned, this study is only focused on the negative part discourse in CSR reports. More insightful studies could be undertaken in other discourse in corporate communication in order to fully understand the discourse.

\section{REFERENCES}

[1] Bansal, P., \& Clelland, I. (2004). Talking trash: Legitimacy, impression management, and unsystematic risk in the contesxt of the natural environment. Academy of Management Journal, 47(1), 93-103. 
[2] Bhatia V (1993) Analysing Genre: Language Use in Professional Settings. New York: Longman.

[3] Bhatia VK (2017) Critical Genre Analysis: Investigating Interdiscursive Performance in Professional Practice. London and New York: Routledge

[4] Bhatia, Vijay K., (2010): "Interdiscursivity in professional communication", Discourse and Communication, 21, 1, (32-50)

[5] Bouten, L., Everaert, P., Van Liedekerke, L., De Moor, L., \& Christiaens, J. (2011, September). Corporate social responsibility reporting: A comprehensive picture? In Accounting Forum (Vol. 35, No. 3, pp. 187-204). Taylor \& Francis.

[6] Carroll, A. 2013. "Corporate social responsibility evolution of a definitional construct," Business and Society 38: 268-951

[7] Catenaccio P (2011) Social and environmental reports: A short-term diachronic perspective on an emerging genre. In: Garzone G and Gotti M (eds) Discourse, Communication and the Enterprise: Genres and Trends. New York: Peter Lang, pp. 169-192.

[8] Deegan C and Rankin M (1996) Do Australian companies report environmental news objectively? An analysis of environmental disclosures by firms prosecuted successfully by the Environmental Protection Authority. Accounting, Auditing \& Accountability Journal. 9(2): 50-67.

[9] Dhaliwal, D. S., Radhakrishnan, S., Tsang, A., \& Yang, Y. G. (2012). Nonfinancial Disclosure and Analyst Forecast Accuracy: International Evidence on Corporate Social Responsibility Disclosure. The Accounting Review, 87(3), 723-759.

[10] Filimon, A. I. 2009. "Kyosei- an example of cultural keyword argumentatively exploited in corporate reporting discourse," Studies in Communication Sciences 9: 131-52.

[11] Flowerdew, J., \& Wan, A. (2010). The linguistic and the contextual in applied genre analysis: The case of the company audit report. English for Specific Purposes, 29, 78-93.

[12] Hahn, R., \& Lülfs, R. (2014). Legitimizing negative aspects in GRI-oriented sustainability reporting: A qualitative analysis of corporate disclosure strategies. Journal of business ethics, 123(3), 401-420.

[13] Jin, Y., Shi, H., \& Zhang, X. (2019). Religious social norms and CSR deficiency disclosure. Asia-Pacific Journal of Accounting \& Economics, 26(4), 409-433.

[14] Krippendorff, K. (2011). Agreement and information in the reliability of coding. Communication Methods and Measures, 5, 93-112.

[15] Li, F. (2008). Annual report readability, current earnings, and earnings persistence. Journal of Accounting and Economics, 45(2-3), 221-247.

[16] Lin, Y. (2019a). Communicating bad news in corporate social responsibility reporting: A genre-based analysis of Chinese companies. Discourse\& Communication.

[17] Lin, Y. (2019b). Legitimating Negative Aspects in Corporate Social Responsibility Reporting: Evidence from China. IEEE Transactions on Professional Communication, 62(3), 263-278.

[18] Lung J (2017) Interdiscursivity in public relations communication: Appropriation of genre and genre resources. HERMES. 27(54): 21-33.

[19] Martin, J. R., \& Rose, D. (2003). Working with discourse: Meaning beyond the clause. London: Continuum.

[20] Martin, J. R., \& White, P. R. R. (2005). The language of evaluation: Appraisal in English. New York, NY: Palgrave Macmillan.

[21] Qian, Y. (2020). A critical genre analysis of MD\&A discourse in corporate annual reports. Discourse \& Communication.

[22] S. Skulstad, “Creating a 'green' image in the public sphere: Corporate environmental reports in a genre perspective," in Handbook of Communication in the Public Sphere. R. Wodak and V. Koller, Eds. Berlin, Germany: De Gruyter Mouton, 2008, pp. 181-201 